\title{
THE EFFECT OF GLUT4 EXPRESSION IN HIPPOCAMPAL NEURONS TO SPATIAL MEMORY OF DIABETES- INDUCED RATTUS NOVERGICUS
}

Herpan Syafii Harahap ${ }^{1}$, Novrita Padauleng ${ }^{2}$, Rizka Vidya Lestari ${ }^{2}$, Nurhidayati Nurhidayati ${ }^{3}$, Anak Agung Ayu Niti Wedayani ${ }^{3}$, Putu Suwita Sari ${ }^{4}$, Hifdzil Haq Muliyana ${ }^{5}$, Ngakan Putu Proudy Laksmana ${ }^{5}$, Aliza Raudatin Sahly ${ }^{5}$

Correspondence: herpanharahap@yahoo.co.id

${ }^{1}$ Department of Neurology, Faculty of Medicine, Universitas Mataram, Mataram, Indonesia.

${ }^{2}$ Department of Histology, Faculty of Medicine, Universitas Mataram, Mataram, Indonesia.

${ }^{3}$ Department of Pharmacology, Faculty of Medicine, Universitas Mataram, Mataram, Indonesia.

${ }^{4}$ Department of Parasitology, Faculty of Medicine, Universitas Mataram, Mataram, Indonesia.

${ }^{5}$ Medical Student, Faculty of Medicine, Universitas Mataram, Mataram, Indonesia.

\author{
Article History: \\ Received: October 3, 2020 \\ Accepted: April 21, 2021 \\ Published: July 1, 2021

\section{Cite this as:} \\ Harahap HS, Padauleng $N$, \\ Lestari RV, Nurhidayati N, \\ Wedayani AAAN, Sari PS, et \\ al.The effect of GLUT4 \\ expression in hippocmpal \\ neurons to spatial memory of \\ diabetes-induced Rattus \\ novergicus. Malang Neurology \\ Journal; 2021.7: 114-119. \\ http://dx.doi.org/10.21776/ub.mnj \\ .2021.007.02.6
}

\section{ABSTRACT}

Background: Identification of appropriate biomarker involved in the pathophysiology of diabetesassociated cognitive decline in animal model is necessary. Glucose transporter 4 (GLUT4) is the component of insulin-dependent neuronal signaling pathway needed for maintaining cognitive function. It is highly expressed in hippocampal neurons.

Objective: To investigate the effect of GLUT4 expression in hippocampal neurons on the spatial memory of diabetes-induced Rattus novergicus.

Methods: This experimental study used 24 male Rattus novergicus divided into control groups terminated on day-0 (C0), $14(\mathrm{C} 1)$ and $28(\mathrm{C} 2)$ and diabetic groups terminated on day-0 (D0), 14 (D1) and 28 (D2). Diabetes was induced using streptozotocin injections intraperitoneally. Spatial memory (travel time) of rats was assessed on day-14 and 28. Brain tissue sampling was performed for assessment of GLUT4 expression using immunohistochemical methods. Significant differences in means of GLUT4 expression and travel time between groups on day-0, 14 and 28 as well as correlation between means of GLUT4 expression and travel time in D1 and D2 were analyzed statistically.

Results: The mean of GLUT4 expression in diabetic group was significantly higher compared to control on day-14, but not on day-0 and 28 . The immunohistochemical examination confirmed this results. There were no significant differences in mean of travel time between control and diabetic groups on day-14 and 28. There were no significant correlation between means of GLUT4 expression and travel time in diabetic groups on day-14 and 28.

Conclusion: The GLUT4 expression of hippocampal neurons did not significantly affect spatial memory of diabetes-induced Rattus novergicus.

Keywords: GLUT4, spatial memory, diabetes mellitus, cognitive decline, animal model

\section{Introduction}

Diabetes mellitus is a component of vascular risk factors that play an important role for cognitive decline, both independently and through its interaction with other vascular risk factors. ${ }^{1,2}$ The prevalence of diabetesassociated cognitive decline varies in several studies, ranged from $2.2-28.8 \% .^{3,4}$ Its prevalence is influenced by many factors, including the differences in clinical and demographic characteristics of the subjects studied as well as the cognitive assessment instruments used. The clinical manifestation of diabetes-associated cognitive decline may ranging from mild to severe forms. ${ }^{5}$

The cognitive domains most affected in diabetes-associated cognitive decline are memory, either verbal or visual type, attention, and executive function. ${ }^{6,7}$ Imaging studies showed that diabetes mellitus was significantly associated with the decrease of hippocampal volume and atrophy of the frontal and temporal lobes. ${ }^{8,9}$ The mechanism underlying the occurrence of diabetes-associated cognitive decline is not well established yet. It is proposed that the disruption of insulin signaling in neurons and neuroinflamation play an important role in its pathogenesis. ${ }^{10}$

Analysis of the role of diabetes mellitus in causing cognitive decline through examination of appropriate biomarkers in brain tissue is important, especially in efforts to improve our understanding of the pathomechanism of diabetes-associated cognitive decline. Therefore, the selection of appropriate biomarker for such study is necessary. Glucose transporter 4 (GLUT4), a glucose transporter isoforms whose regulation of expression is fully controlled by insulin, needs to be considered as an important component of the insulin-dependent neuronal signaling pathway which is needed for maintaining the cognitive function. ${ }^{11}$ GLUT4 expression is highly increase in the hippocampal neurons, a population of neuron which 
is important in carrying out cognitive functions. ${ }^{12,13}$ Thus, GLUT4 expression in these neurons can be considered as an appropriate biomarker for the investigation of the pathomechanism of diabetes-associated cognitive decline. ${ }^{14}$

The animal model suitable for the investigation of the pathogenesis of diabetes-associated cognitive decline and widely used in many studies is diabetes-induced Rattus novergicus. ${ }^{15,16,17}$ The method of induction of diabetes in those animal model most commonly used is by chemically destruction of pancreatic beta cells using alloxan ${ }^{18,19}$ and streptozotocin. ${ }^{20,21}$ Between these two chemical induction methods, streptozotocin is superior since it has greater range of toxic doses compared to alloxan. ${ }^{22}$ Our previous studies used a combination of streptozotocin and nicotinamide in the chemically diabetes induction in Rattus novergicus. ${ }^{23}$ The use of nicotinamide in the chemically diabetes induction using streptozotocin in animal model was aimed to prevent the excessive damage of pancreatic beta cell which is lethal to these animal model. ${ }^{24}$ The impact of the pancreatic beta cells destruction related to this chemically diabetes induction is the decrease of the insulin secretion.

Evaluation of cognitive function in animal model can be performed by using several tests, including the Morris Water Maze (MWM) test, Y-Maze Spontaneous Alternation test, Passive Avoidance test and Rotarod test. ${ }^{25}$ Among them, the Morris Water Maze test is the widely used test in previous studies since it consist of simple procedure but with high reliability in evaluating spatial memory. The procedure of this test including repeated training of sessions of swimming in a standardized chamber of water to find a platform submerged in this pool of water and stand on it. This test has complexity in measuring the parameter of travel distance, which measure the distance the rat traveled when starting to swim until it reached the platform, so the measurement of this parameter requires special computer program. ${ }^{26}$ However, these technical difficulties can be overcome by replacing this parameter with another one, called travel time, which measure the time taken by the rat when starting to swim until it reach the platform. ${ }^{27,28}$

This study aims to investigate the effect of GLUT4 expression on hippocampal neurons on the spatial memory of Rattus novergicus rats induced diabetes by injection of streptozotocin and nicotinamide. This was our effort to prove the role of GLUT4 in the pathomechanism of diabetes-associated cognitive decline. Evaluation of spatial memory is performed by using MWM test as previously described. The use of animal models and the induction technique used in this study refer to our previous studies.

\section{Methods}

The animal models used in this experimental study were 24 male Rattus novergicus strain wistar rats aged 2-3 months, body weight 200-300 grams, and healthy without physical defects. Rats are placed in cages with size of $50 \times 60 \mathrm{~cm}$ and each cage contains 4 rats. Rats were divided into six groups and each group was consisted of 4 rats. Those six groups were the control group to be terminated on day- 0 of observation $(\mathrm{C} 0)$, the control group to be terminated on day-14 of observation (C1), the control group to be terminated on day-28 of observation (C2), the diabetic group to be terminated on day-0 of observation (D0), the diabetic group to be terminated on day-14 of observation (D1), and the diabetic group to be terminated on day-28 of observation (D2). Rats were adapted for 7 days and given standard food and drink every day. This study has received ethical approval from the Komisi Etik Penelitian Kesehatan Universitas Mataram with Number 101 / UN18.F7 / ETIK / 2019.

Twelve Rattus novergicus rats from the diabetic group divided into D0, D1 and D2 were injected with a single dose of $110 \mathrm{mg} / \mathrm{kgBW}$ nicotinamide intraperitoneally. A single dose of intraperitoneal injection of streptozotocin 70 $\mathrm{mg} / \mathrm{kgBW}$ was performed in those three groups, 15 minutes after administration of nicotinamide. Hyperglycemia will be achieved 72 hours after induction confirmed by fasting blood glucose levels test using glucometer. All procedures of diabetes induction was conducted in The Integrated Laboratory of the Faculty of Medicine, Universitas Mataram.

The day of confirmation of hyperglycemia by measuring the fasting blood glucose level, which is 72 hours post induction, is determined as the day-0 of observation. Thus, measurement of fasting blood glucose levels for D0, D1 and D2 was conducted on day-0, 14 and 28 of observation. Blood samples were taken from tail of the rats that had been previously incised aseptically. On day-0, termination and sampling of brain tissue in D0 as well as C0 groups were conducted after fasting blood samples of D0 and other diabetic groups (D1 and D2) were obtained. The examination of fasting blood glucose levels using glucometer was conducted in The Integrated Laboratory of the Faculty of Medicine, Universitas Mataram.

Both the spatial memory training and assessment were conducted in four groups $(\mathrm{C} 1, \mathrm{D} 1, \mathrm{C} 2$, and D2) using the Morris Water Maze (MWM) test. The spatial memory training was conducted on day 1 to 4 of observation, while the assessment of spatial memory was conducted on day-14 and 28 of observation. This test was using an instrument and procedures as described in previous study. ${ }^{29}$ On day-14, a spatial memory cognitive session was conducted in the same manner in day 1 to 4 in all four groups $(\mathrm{C} 1, \mathrm{D} 1, \mathrm{C} 2$, and D2) and followed by termination and sampling of brain tissue in groups $\mathrm{C} 1$ and D1. On day-28, a spatial memory cognitive session was also conducted in the C2 and D2 groups and was followed by termination and sampling of brain tissue in both groups. The mean of travel time of each rats from the four quadrants was measured on day-14 and 28 of observation.

Termination of rats for brain tissue sampling was performed on day-0 (C0 and D0), 14 (C1 and D1), and 28 (C2 and D2) of observation. Termination of animal models was conducted using lethal doses of chloroform. Rats brain tissue was immediately taken by opening the cranium bones. The brain tissue was fixed in $10 \%$ formalin PBS solution. The process of slicing the hippocampal tissue and making preparations for GLUT4 immunohistochemical examination was conducted in the Histology and Cell Biology Laboratory of Faculty of Medicine, Public Health and Nursing, Universitas Gadjah Mada. The GLUT4 expression of hippocampal neurons from all six groups of animal models was assessed using immunohistochemical 
methods. Sliced hippocampus samples prepared for examination of GLUT4 expression were dropped with xylol I, xylol II, ethanol $100 \%$, ethanol $95 \%$, ethanol $90 \%$, ethanol $80 \%$, ethanol $70 \%$, and distilled solution. The slices were stored in a $37^{\circ} \mathrm{C}$ incubator for 3 days, then stored on a storage shelves until being used for immunohistochemical staining. An endogenous peroxidase blocking process was performed using $\mathrm{H}_{2} \mathrm{O}_{2} 0.3 \%$, retrieval antigen with HIER (Heat Induced Epitope Retrieval) technique using TRIS EDTA buffer $\mathrm{pH} 9.0$ at moderate temperature for 20 minutes, and washed with PBS solution at $\mathrm{pH}$ 7.4. The slices were given a sniper background for 10 minutes to prevent binding with non-specific proteins and were incubated with anti-GLUT4 primary antibodies (polyclonal antibodies, abcam ab33780) overnight at $4^{\circ} \mathrm{C}$. In the next step, the slices were incubated with secondary antibodies (trekki universal link) for 10 minutes and washed using PBS pH 7.4 for 5 minutes 3 times. At the final step, Streptavidin peroxidase (Track Avidin HRP label) was given to the slices for 10 minutes, then washed again using PBS pH 7.4. Betazoid DAB 1:100 for 5 minutes without light was given for visualization and followed by washing using distilled water. Immunohistochemical examination of GLUT4 hippocampus was conducted in the Anatomical Pathology Laboratory of the Faculty of Medicine, Public Health and Nursing, Universitas Gadjah Mada.

Data analysis was performed using a computer program using independent t, Mann-Whitney, One-way ANOVA, Kruskal-Wallis, and Pearson correlation tests. Statistical results were significant if the p-value $<0.05$.

\section{Results}

The mean of fasting blood glucose (FBG) level of diabetesinduced rats (D0, D1 and D2) in 72 hours post induction were $211.1 \pm 27.7 \mathrm{mg} / \mathrm{dl} \quad(\mathrm{n}=12)$. This result showed that hyperglycemic state was achieved in both groups in day-0 of observation. The mean of FBG level of diabetic groups on day-14 and 28 were $93.4 \pm 5.9 \mathrm{mg} / \mathrm{dl}$ and $139.5 \pm 32.2$. The FBG levels both on day-14 and 28 were lower compared to FBG level on day-0. There were significant difference in the mean of FBG level among day-0, 14 and 28 in Kruskal-Wallis test $(\mathrm{p}=0.000)$. In post hoc analysis using Mann-Whitney test, the FBG level on day-0 was significantly higher compared to its level on day-14 $(\mathrm{p}=0.000)$, but not on day-28 $(\mathrm{p}=0.058)$. The FBG level on day-14 was significantly higher compared to its level on day-28 ( $\mathrm{p}=0.048)$ (Figure 1).

The mean of GLUT4 expression of hippocampal neurons in diabetic group was significantly higher compared to control group on day-14 (D1vsC1; $\mathrm{p}=0.006)$ in independent t-test, but not on day-0 (D0 vs C0; $\mathrm{p}=0.486$ ) and day-28 (D2 vs $\mathrm{C} 2 ; \mathrm{p}=0.057$ ) in Mann-Whitney tests (Figure 2A). Based on the time of observation, the mean of GLUT4 expression in diabetic group among day-0 (D0), day-14 (D1) and day-28 (D2) of observations was significantly difference $(\mathrm{p}=0.039)$ in One-way ANOVA test, but in post hoc Tukey, there were no significant difference in the mean of GLUT4 expression between D0 and D1 $(\mathrm{p}=0.068), \mathrm{D} 0$ and D2 $(\mathrm{p}=0.055)$, and D1 and D2 $(\mathrm{p}=0.990)$ (Figure 2B). The immunohistochemical examination confirmed this results (Figure 2C-H).

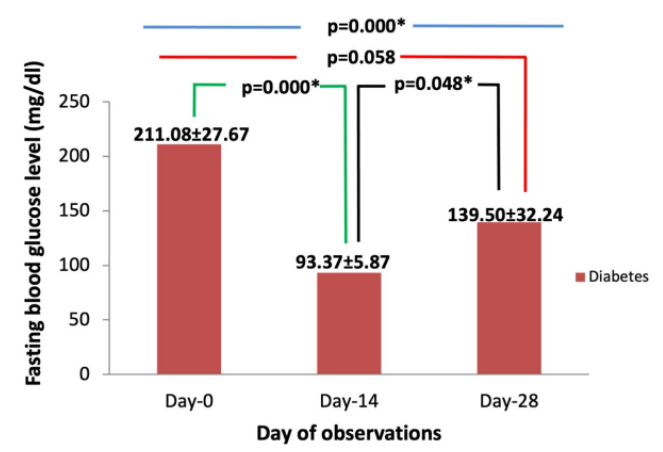

Figure 1. The comparison of mean of fasting blood glucose of diabetic rats based on different day of observation. Wilcoxon test (blue band) showed significant difference in mean of fasting blood glucose among diabetic rats on different day of observation. Post hoc Mann-Whitney test showed that hyperglycemic state achieved on day- 0 were decrease significantly on day-14 (green band), but not significantly on day-28 (red band). The mean of fasting blood glucose on day-28 was increased significantly compared to those on day-14 (black band). Note: $*$ indicate $\mathrm{p}<0.05$.

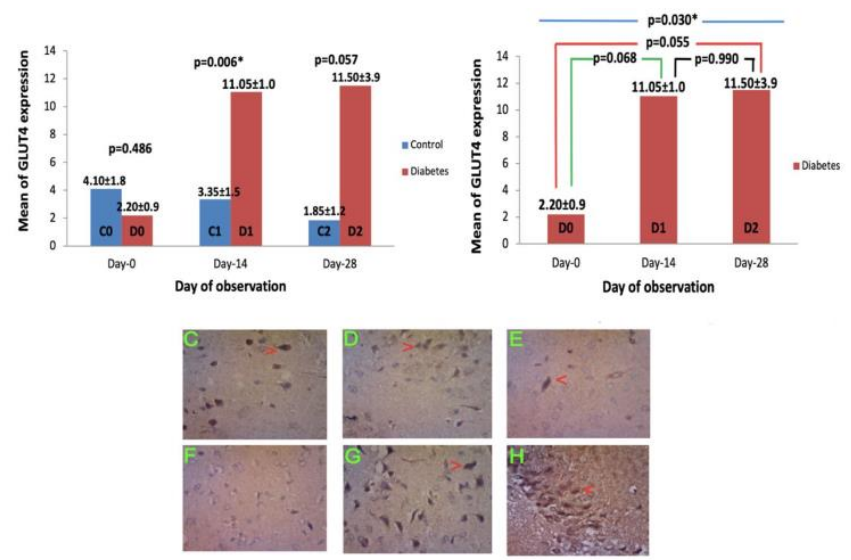

Figure 2. The comparison of mean of GLUT4 expression between diabetic and control groups on different day of observation. (A) The mean of GLUT4 expresion in diabetic group was significantly higher compared to control on day-14, but not on day-0 and 28. (B) One-way ANOVA test showed significant difference in mean of GLUT4 expression of diabetic rats in different day of observation (blue band), but post hoc Tukey showed no significant difference among those groups (green, red, and black bands). The results of immunohistochemical examination in control on day-0 (C), day-14 (D) and day-28 (E) as well as in diabetic groups on day-0 (F), day

$14(\mathrm{G})$ and day-28 (H) confirmed those findings. Neurons that expressed GLUT4 are shown as blue-colored nuclei surrounded by brown-colored cystoplasm on immunohistochemical examination (arrowhead). Note: $*$ indicate $\mathrm{p}<0.05$.

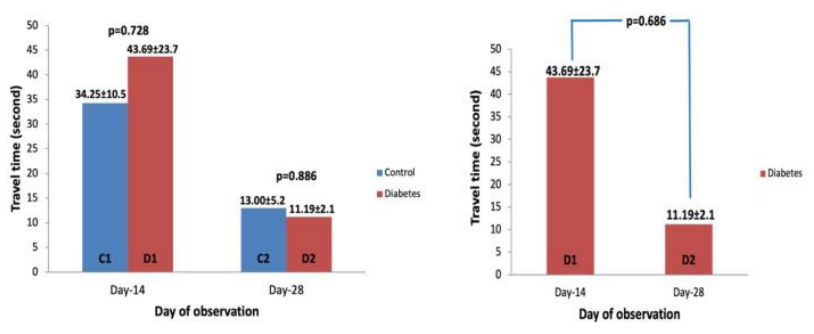

Figure 3. The comparison of mean of travel time between diabetic and control groups. (A) The mean of travel time of diabetic groups was not significantly slower compared to control on day-14 and 28. (B) The mean of travel time of diabetic groups was also not significantly different based on day of observation (blue band). 
As noted earlier, the assessment of spatial memory function in this study was represented by mean of travel time of the rats in both control and diabetic group on day-14 and 28 of observations. There were no significant difference in the mean of travel time between control and diabetic groups both on day-14 (C1vsD1; $\mathrm{p}=0.728)$ in independent t-test and day-28 $(\mathrm{C} 2 \mathrm{vsD} 2 ; \mathrm{p}=0.886)$ in Mann-Whitney test (Figure $3 \mathrm{~A}$ ). Based on the time of observation, there was also no significant mean of travel time difference in diabetic group between day-14 (D1) and day-28 (D2) of observations $(\mathrm{p}=0.686)$ in Mann-Whitney test (Figure 3B). There were no significant correlation between the mean of GLUT4 expression and the mean of travel time in diabetic group both on day-14 $(\mathrm{p}=0.755)$ and $28(\mathrm{p}=0.841)$ in the Pearson correlation tests

\section{Discussion}

Epidemiological studies show that cognitive decline is one of the important complications of diabetes mellitus, eventhough its mechanism is still poorly understood. ${ }^{1,3}$ Current available drugs are effective only in regulating blood glucose levels, but not in preventing diabetesassociated cognitive decline. ${ }^{30,31}$ Better understanding of the pathophysiology of diabetes-associated cognitive dysfunction is needed in order to identify a biomarker which has important roles in the regulation of glucose homeostasis as well as neuroprotection against diabetesassociated cognitive decline. At present, many studies have been carried out for this purpose using experimental animals, including diabetes-induced Rattus novergicus. ${ }^{15,16}$

Glucose transporter 4 (GLUT4) is the appropriate candidate of biomarker that play the important roles in the regulation of cell glucose homeostasis and neuroprotection, for at least two important reasons. First, the GLUT4 protein is one of the glucose transporter isoforms facilitating transport of glucose into cells. ${ }^{32}$ Second, GLUT4 protein is also expressed in the brain, including in the hippocampus. ${ }^{11,23,33}$ The hippocampus is a well known as brain structure that carrying out memory function, one of domains of cognitive function.

As a glucose transporter, the GLUT4 protein acts as a part of integral proteins located at the cell membrane, thus facilitating influx glucose into cell. The regulation of GLUT4 protein expression is highly dependent on insulin activity. Thus, this protein is an important part of the insulin signaling pathway in maintaining cell glucose homeostasis. ${ }^{34}$ Consistent with the role of GLUT4 in neuronal glucose homeostasis regulation, the result of this study showed that the mean of GLUT4 expression in hippocampal neurons was significantly higher in the diabetic rats compared to control rats on day-14, but not on day- 0 and 28. This was consistent with the results of previous studies. ${ }^{23}$ At day- 0 , the mean of GLUT4 expression in diabetic rats, although not significantly different, was lower than in control. It was probably due to the decreased of insulin production related to streptozotocin-induced $\beta$-cells damage. ${ }^{35}$ The mean of GLUT4 expression of hippocampal neurons in the diabetic rats on day-28, although not significantly different from the control, still tend to be higher compared to the those mean in diabetic rats on day- 0 and comparable to those mean in diabetic rats on day-14 (Figure 2A-B). These results had been confirmed by immunohistochemical examination (Figure 2C-H). The relatively high mean of GLUT4 expression of hippocampal neurons on days-14 and 28 compared to day- 0 was likely due to partial regeneration of pancreatic $\beta$-cells as well as insulin production on day-14 of observation. ${ }^{36}$ The regeneration of pancreatic $\beta$-cells after streptozotocin-induced pancreatic $\beta$-cell damage might be associated to the co-administration of nicotinamides in the time of diabetes induction using streptozotocin aimed to prevent streptozotocin-induced excessive $\beta$-cells damage. ${ }^{24}$ This regeneration process might partially explained the occurrence of fasting blood glucose regulation from hyperglycemic state on day-0 to normal level on day-14 and 28 in diabetic rats (Figure 1).

As stated earlier, GLUT4 protein is widely expressed in the hippocampal neurons, a brain structure that subserve memory function. Recent study conducted by PearsonLeary and McNay shows that blockade of GLUT4 protein in hippocampal neurons causes a decrease in processing and regulation of memory. ${ }^{12}$ Administration of GLUT4 blockers, indinavir (protease inhibitors), in HIV patients is associated with the occurrence of cognitive decline. ${ }^{37}$ Based on these facts, it can be proposed that GLUT4 protein has potential role in cognitive function. The result of the present study showed that there was no correlation between the mean of GLUT4 expression of hippocampal neurons and the travel time of diabetic rats on day-14 and 28 of observations (Figure 3A-B). These results were contradictory to the available facts described above. These might be due to lack of exposure of neurons of diabetic rats to hyperglycemic state, either related to the length of time of hyperglycemic exposure or the stability of the hyperglycemic state during observation. Alternatively, this might be true that GLUT4 protein did not involved in cognitive function in diabetic rats. In theory, the neurodegeneration process associated with diabetes mellitus that lead to decrease of cognitive function, including memory function, can occur after prolonged exposure to neurons with hyperglycemic state. ${ }^{38}$ Studies conducted by Darwatik et al. and Prabawati et al. showed that diabetic rats had significantly different mean travel time with healthy controls after the diabetic group rats were given hyperglycemia exposure for 6 weeks, 2 weeks longer than the current study. ${ }^{27,28}$ There is currently no ideal time reference for exposure to hyperglycemia in diabetic rats that can significantly influence the cognitive function of these experimental animals.

Besides the length of time of exposure to hyperglycemia, another factor probably influencing the results of this study was the decrease of fasting blood glucose levels in diabetic rats to the normal range, both on day-14 and 28 of observation, which showed low stability of the hyperglycemic condition during period of observation. This is probably related to the regeneration of pancreatic $\beta$-cells, as previously explained, which causes insulin secretion so that the regulation of blood glucose levels leads to its normal value. Thus, the relatively short time of exposure to hyperglycemia, the lack of stability of hyperglycemic state 
during period of observation, and no measurement of insulin levels at different time of observation aimed to evaluate the significance of pancreatic beta cell regeneration processes are the limitation of this study which need to be corrected if similar studies will be carried out. Departing from the existing data, there are several biomarkers, other than GLUT4 protein, involved in the insulin signaling cascade which are also potential to be investigated for their role in the pathogenesis of diabetesassociated cognitive decline and to be used as a therapeutic target for those condition. ${ }^{10,39}$

\section{Conclusion}

In conclusion, the GLUT4 expression of hippocampal neurons in this study did not significantly affect spatial memory of diabetes-induced Rattus novergicus. This result might be associated with the limitation of exposure time to hyperglycemia and the lack of stability of hyperglycemic state during period of observation in diabetic rats.

\section{Acknowledgement}

Authors thank to Lembaga Penelitian dan Pengabdian kepada Masyarakat (LPPM) of Univeritas Mataram that support this research.

\section{Conflict of Interest}

The authors declare that there is no conflict of interst.

\section{References}

1. Biessels GJ, Despa F. Cognitive decline and dementia in diabetes mellitus: mechanisms and clinical implications. Nat Rev Endocrinol; 2018. 14(10):591604. DOI: $10.1038 / \mathrm{s} 41574-018-0048-7$

2. Harahap HS, Indrayana Y, Lestari R. The Correlation of Obstructive Sleep Apnea Risk level and Metabolic Syndrome with Global Cognitive Functions. J Kedokt Brawijaya; 2018. 30(2):133-7.

DOI: 10.21776/ub.jkb.2018.030.02.10

3. Lavielle P, Talavera JO, Reynoso N, González M, Gomez-Diaz RA, Cruz M, et al. Prevalence of Cognitive decline in Recently Diagnosed Type 2 Diabetes Patients: Are Chronic Inflammatory Diseases Responsible for Cognitive Decline?. PLoS One; 2015. 10(10):e0141325.

DOI: 10.1371/journal.pone.0141325

4. Verny C, Doucet J, Bauduceau B, Constans T, Mondon K, Le Floch JP. Prevalence of cognitive decline and associated factors in elderly type 2 diabetic patients at inclusion in the GERODIAB cohort. Eur Geriatr Med; 2015. 6(1):36-40.

DOI: http://dx.doi.org/10.1016/j.eurger.2014.10.006

5. Kravitz E, Schmeidler J, Beeri MS. Type 2 Diabetes and Cognitive Compromise: Potential Roles of Diabetes-Related Therapies. Endocrinol Metab Clin North Am; 2013. 42(3):489-501.

DOI: $10.1016 /$ j.ecl.2013.05.009

6. Hopkins R, Shaver K, Weinstock RS. Management of Adults With Diabetes and Cognitive Problems. Diabetes Spectr; 2016. 29(4):224-37.

DOI: $10.2337 / \mathrm{ds} 16-0035$
7. Palta P, Schneider ALC, Biessels GJ, Touradji P, HillBriggs F. Magnitude of Cognitive Dysfunction in Adults with Type 2 Diabetes: A Meta-analysis of Six Cognitive Domains and the Most Frequently Reported Neuropsychological Tests Within Domains. J Int Neuropsychol Soc; 2014. 20(3):278-91.

DOI: $10.1017 / \mathrm{S} 1355617713001483$

8. Moran C, Phan TG, Chen J, Blizzard L, Beare R, Venn A, et al. Brain Atrophy in Type 2 Diabetes. Diabetes Care; 2013. 36:4036-42.

DOI: $10.2337 / \mathrm{dc} 13-0143$

9. Moheet A, Mangia S, Seaquist ER. Impact of diabetes on cognitive function and brain structure. Ann N Y Acad Sci; 2015. 1353:60-71.

DOI: $10.1111 /$ nyas. 12807

10. Zilliox LA, Chadrasekaran K, Kwan JY, Russel JW. Diabetes and Cognitive decline. Curr Diab Rep; 2016. 16(9):87. DOI:10.1007/s11892-016-0775-x

11. Shah K, DeSilva S, Abbruscato T. The Role of Glucose Transporters in Brain Disease : Diabetes and Alzheimer's Disease. Int J Mol Sci; 2012. 13:1262955. DOI: 10.3390/ijms 131012629

12. Pearson-Leary J, McNay EC. Novel Roles for the Insulin-Regulated Glucose Transporter-4 in Hippocampally Dependent Memory. J Neurosci; 2016. 36(47):11851-64.

DOI: $10.1523 /$ JNEUROSCI.1700-16.2016

13. Jurcovicova J. Glucose transport in brain - effect of inflammation. Endocr Regul; 2014. 48:35-48.

DOI: 10.4149/endo_2014_01_35

14. Blázquez E, Velázquez E, Hurtado-Carneiro V, RuizAlbusac JM. Insulin in the brain: its pathophysiological implications for states related with central insulin resistance, type 2 diabetes and Alzheimer's disease. Front Endocrinol (Lausanne); 2014. 5:161. DOI: 10.3389/fendo.2014.00161

15. Liu X, Liu M, Mo Y, Peng H, Gong J, Li Z, et al. Naringin ameliorates cognitive deficits in streptozotocin-induced diabetic rats. Iran J Basic Med Sci; 2016.19:417-22. Avalaible form: https://www.ncbi.nlm.nih.gov/pmc/articles/PMC4887 $715 /$

16. Moghadamnia AA, Hakiminia S, Baradaran M, Kazemi S, Ashrafpour M. Vitamin D Improves Learning and Memory Impairment in StreptozotocinInduced Diabetic Mice. Arch Iran Med; 2015. 18(6):362-6. DOI: 015186/aim.007

17. Pintana H, Apaijai N, Chattipakorn N, Chattipakorn SC. DPP-4 inhibitors improve cognition and brain mitochondrial function of insulin-resistant rats. J Endocrinol; 2013. 218:1-11. DOI: 10.1530/JOE-120521

18. Yin P, Wang Y, Yang L, Sui J, Liu Y. Hypoglycemic Effects in Alloxan-Induced Diabetic Rats of the Phenolic Extract from Mongolian Oak Cups Enriched in Ellagic Acid, Kaempferol and Their Derivatives. Molecules; 2018. 23:1046.

DOI: 10.3390/molecules23051046

19. Andayani Y. Efek Ekstrak Buncis (Phaseolus vugaris L) terhadap Uptake 14C-D-Glukosa Otot pada Tikus Diabetes. J Kedokt Unram; 2018. 7(2):12-5.

20. Mahfud RA, Lyrawati D, Sarwono I. Effect of Alpha Lipoic Acid on MDA Levels and Histology of Brain 
in Type 1 DM. Malang Neurol J; 2017. 3(1):23-9. DOI: http://dx.doi.org/10.21776/ub.mnj.2017.003.01.5

21. Kristianto H, Mardiati NPJ. The Effects of Earthworms (Pheretima aspergillum) Ethanol Extract Toward the Improvement of nerve Fibers Density in Diabetic Ulcers Care Degree II of Rats Wistar. Malang Neurol J; 2017. 3(2):61-72. DOI: http://dx.doi.org/10.21776/ub.mnj.2017.003.02.3

22. Tripathi V, Verma J. Different Models Used To Induce Diabetes: A Comprehensive Review. Int J Pharm Pharm Sci; 2014. 6(6):29-32.

23. Harahap HS, Padauleng N, Nurhidayati N, Ekawanti A. Expression of GLUT4 in Hippocampal Neurons of Streptozotocin and Nicotinamide-induced Diabetic Rattus Novergicus. J Kedokt Brawijaya; 2019. 30(3):197-201. http://dx.doi.org/10.21776/ub.jkb.2019.030.03.6

24. Kishore L, Kajal A, Kaur N. Role of Nicotinamide in Streptozotocin Induced Diabetes in Animal Models. J Endocrinol Thyroid Res; 2017. 2(1):555577. DOI: 10.19080/jetr.2017.02.555577

25. Xourgia E, Papazafiropoulou A, Melidonis A. Antidiabetic treatment on memory and spatial learning: From the pancreas to the neuron. World J Diabetes; 2019. 10(3):169-80. DOI: 10.4239/wjd.v10.i3.169

26. Vorhees C V, Williams MT. Value of water mazes for assessing spatial and egocentric learning and memory in rodent basic research and regulatory studies. Neurotoxicol Teratol; 2014. 45:75-90. DOI: http://dx.doi.org/10.1016/j.ntt.2014.07.003

27. Darwatik D, Ratnawati R, Rianawati SB, Sarwono I. Effect of Purple Sweet Potato Antocyanin towards TNF- $\alpha$, Apoptosis, and Spatial Memory in Hippocampus of Rat Model of Diabetes Mellitus. J Kedokt Brawijaya; 2017. 30(1):12-8.

DOI: http://dx.doi.org/10.21776/ub.jkb.2018.030.01.3

28. Prabawati RK, Ratnawati R, Rahayu M, Prakosa AG. Effect Anthocyanin of Purple Potato Gunung Kawi on MDA Levels, Expression of Caspase-3, and Spatial Memory Function on Diabetic Wistar Rats. Malang Neurol J; 2019. 5:34-41. DOI: http://dx.doi.org/10.21776/ub.mnj.2019.005.01.6

29. Rahman A, Rao MS, Khan KM. Intraventricular infusion of quinolinic acid impairs spatial learning and memory in young rats: a novel mechanism of leadinduced neurotoxicity. J Neuroinflammation; 2018.
15:263. DOI: https://doi.org/10.1186/s12974-018$1306-2$

30. Wennberg AM V, Hagen CE, Edwards K, Roberts RO, Machulda MM, Knopman DS, et al. Association of antidiabetic medication use, cognitive decline, and risk of cognitive decline in older people with type 2 diabetes: results from the population-based Mayo Clinic Study of Aging. Int J Geriatr Psychiatry; 2018. 33(8):1114-20. DOI: $10.1002 /$ gps.4900

31. Herath PM, Cherbuin N, Eramudugolla R, Anstey KJ. The Effect of Diabetes Medication on Cognitive Function: Evidence from the PATH Through Life Study. Biomed Res Int; 2016. 2016:7208429.

DOI: http://dx.doi.org/10.1155/2016/7208429

32. Hajiaghaalipour F, Khalilpourfarshbafi M, Arya A. Modulation of Glucose Transporter Protein by Dietary Flavonoids in Type 2 Diabetes Mellitus. Int J Biol Sci; 2015. 11(5):508-24. DOI: 10.7150/ijbs.11241

33. Ashrafi G, Wu Z, Farrell RJ, Ryan TA. GLUT4 Mobilization Supports Energetic Demands of Active Synapses. Neuron; 2017. 93(3):606-15.

DOI: http://dx.doi.org/10.1016/j.neuron.2016.12.020

34. Bogan JS. Regulation of Glucose Transporter Translocation in Health and Diabetes. Annu Rev Biochem; 2012. 81:507-32. DOI: 10.1146/annurevbiochem-060109-094246

35. Olson AL. Regulation of GLUT4 and InsulinDependent Glucose Flux. ISRN Mol Biol; 2012. 2012:856987. DOI: $10.5402 / 2012 / 856987$

36. Grossman EJ, Lee DD, Tao J, Wilson RA, Park S, Bell GI, et al. Glycemic Control Promotes Pancreatic Beta-Cell Regeneration in Streptozotocin-Induced Diabetic Mice. PLoS One; 2010. 5(1):e8749.

DOI: 10.1371/journal.pone.0008749

37. Mcnay EC, Pearson-leary J. GluT4 : A central player in hippocampal memory and brain insulin resistance. Exp Neurol; 2020. 323:113076.

DOI: https://doi.org/10.1016/j.expneurol.2019.113076

38. Yu-bin J, Zeng-yi L, Guo-song X, Chi W, Hong-jian Z. Study on cognitive decline in diabetic rats by different behavioral experiments. IOP Conf Ser Earth Environ Sci; 2017. 100:012050. DOI:

39. Kuga GK, Muñoz VR, Gaspar RC, Nakandakari SCBR, da Silva ASR, Botezelli JD, et al. Impaired insulin signaling and spatial learning in middle-aged rats: The role of PTP1B. Exp Gerontol; 2018. 104:6671. DOI: https://doi.org/10.1016/j.exger.2018.02.005 